\title{
Implants in patients with oral manifestations of autoimmune or muco-cutaneous diseases - A systematic review
}

\author{
Frank P. Strietzel ${ }^{1}$, Andrea M. Schmidt-Westhausen ${ }^{1}$, Konrad Neumann ${ }^{2}$, Peter A. Reichart ${ }^{1}$, Jochen Jackowski ${ }^{3}$ \\ ${ }^{1}$ Charité - Universitaetsmedizin Berlin / Charité Centre 3 for Dental, Oral, and Maxillary Medicine, Department for Oral Medi- \\ cine, Dental Radiology, and Oral Surgery \\ ${ }^{2}$ Charité - Universitaetsmedizin Berlin, corporate member of Freie Universitaet Berlin, Humboldt-Universitaet zu Berlin, and \\ Berlin Institute of Health (BIH), Institute of Biometry and Clinical Epidemiology \\ ${ }^{3}$ Department of Oral Surgery and Dental Emergency Care, Faculty of Health, School of Dentistry Witten/Herdecke University, \\ North Rhine-Westphalia
}

Correspondence:

Charité - Universitaetsmedizin Berlin

Charité Centre 3 for Dental, Oral, and Maxillary Medicine

Department for Oral Medicine

Dental Radiology, and Oral Surgery

Assmannshauser Str. 4-6

14197 Berlin

Germany

frank.strietzel@charite.de

\begin{abstract}
Strietzel FP, Schmidt-Westhausen AM, Neumann K, Reichart PA, Jackowski J. Implants in patients with oral manifestations of autoimmune or muco-cutaneous diseases - A systematic review. Med Oral Patol Oral Cir Bucal. 2019 Mar 1;24 (2):e217-30.

http://www.medicinaoral.com/medoralfree01/v24i2/medoralv24i2p217.pdf
\end{abstract}

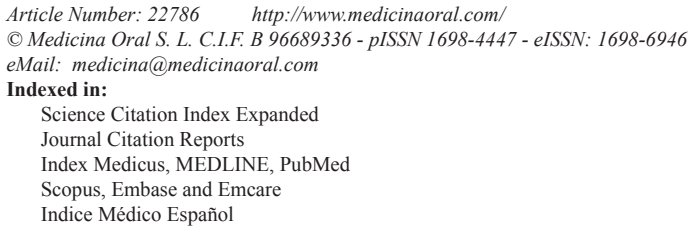

\footnotetext{
Abstract

Background: To give an overview on implant survival rates in patients with oral manifestations of systemic autoimmune (oral Lichen planus (oLp), Pemphigus (Pe)), muco-cutaneous (Epidermolysis bullosa (EB)), autoimmune multisystemic rheumatic diseases (Sjögren's syndrome (SjS), systemic Lupus erythematosus (sLE), or systemic Sclerosis (sSc)).

Material and Methods: Systematic literature review (PubMed/Medline, Embase) using MESH and search term combinations, published between 1980 and August 2018 in English language reporting on dental implant-prosthetic rehabilitation of patients with oLp, Pe, EB, SjS, sLE, sSc, study design, age, gender, follow-up period ( $\geq$ 12 months), implant survival rate. Implant-related weighed mean values of implant survival rate (wmSR) were calculated.

Results: After a mean follow-up period (mfp) of 44.6 months, a wmSR of $98.3 \%$ was calculated from data published for patients with oLp (100 patients with 302 implants). Data of 27 patients (152 implants) with EB revealed wmSR of $98.7 \%$ following mfp of 32.6 months. For 71 patients (272 implants) with SjS, wmSR was $94.2 \%$ following a mfp of 45.2 months, and for 6 patients (44 implants) with sSc, wmSR was $97.7 \%$ after mfp of 37.5 months. One case report on one patient each with Pe (two implants) as well as sLE (6 implants) showed $100 \%$ SR following at least 24 months.
} 
Conclusions: Guidelines regarding implant treatment of patients with oLp, Pe, EB, SjS, sLE or sSc do not exist nor are contraindicating conditions defined. Implant survival rates of patients affected are comparable to those of healthy patients. For implant-prosthetic rehabilitation of patients with Pe and sLE no conclusions can be drawn due to lack of sufficient clinical data. Implant-prosthetic treatment guidelines regarding healthy patients should be strictly followed, but frequent recall is recommended in patients affected with oLp, SjS, EB, SSc, Pe or sLE.

Key words: Dental implants, implant supported prosthesis, oral lichen planus, Sjögren's syndrome, epidermolysis bullosa, systemic sclerosis, pemphigus, systemic lupus erythematosus.

\section{Introduction}

Survival and success rates of implant-prosthodontic rehabilitations in patients without compromised general health conditions have been reported remarkably high even in mid- and long-term observations, after followup periods of up to 10 or exceeding 10 years (1).

Although several conditions still are considered risk factors for dental implant prognosis in medically compromised patients, there are only few absolute contraindications for this treatment option. Thus, disease control of conditions increasing the risk, and individualized risk-benefit assessment prior to dental implant therapy may be considered more important than the disorder or risky condition itself (2). However, dental implant therapy is a viable treatment option even in these patients, revealing satisfying success rates of implant-borne prosthodontic treatment, suggesting that these patients might have a benefit from this treatment option. Moreover, these results encourage to overcome limitations of indications for dental implant treatment under reasonable and careful stepwise treatment regimen as there are interdisciplinary approach, full therapy adherence by the patients as well as strict conditions of tight recall intervals.

Oral manifestations of certain non-infectious systemic diseases - among them autoimmune, ulcerative, bullous, or fibrous - are frequently aggravated by secondary effects of the underlying pathosis in patients suffering from oral Lichen planus (oLp), pemphigus (Pe), Epidermolysis bullosa (EB), Sjögren's syndrome (SjS), systemic Lupus erythematosus (sLE), or systemic sclerosis (sSc).

These patients suffer from inflammatory, ulcerous, erosive lesions, sicca symptoms, scar formation, or limitation of mouth opening. Secondary effects of these diseases are compromised eating and swallowing, xerostomia, enhanced risk of caries and periodontitis decay, alveolar ridge atrophy, scar tissue formation, enhanced risk of oral squamous cell carcinoma, and comprise side effects of systemic anti-inflammatory or immune-modulating medication. Thus, all these patients have in common a significant reduction of quality of life. Moreover, oral hygiene, dental treatment interventions and especially wearing mucosal-borne dentures are impeded. Therefore, the question arises, if these patients might benefit from implant-borne prostheses, to avoid extensive contact between prostheses and the oral mucosa.

The aim of this systematic review of the literature was to reveal, if implant prosthetic treatment of patients suffering from oLp, Pe, EB, SjS, sLE or sSc can be considered a promising treatment option.

\section{Material and Methods}

The focused question was: which implant survival rates were reported in patients suffering from mucocutaneous or autoinflammatory diseases oLp, Pe, EB, SjS, sLE or $\mathrm{sSc}$ ?

A systematic literature search was performed, using electronic literature databases (PubMed/Medline, Embase) and MESH and search term combinations (see Table 1). The systematic review of the literature was done related to the PICO format. Publications reporting on patients suffering from oLp, Pe, EB, SjS, sLE or sSc (population), undergoing clinical use of dental implant-prosthetic rehabilitation (intervention) and revealing study design, age, gender, number of patients and implants, follow-up period of or exceeding 12 months and implant survival rate (outcome), and published between 1980 and December 2017 in English or German language were included. A control group was lacking in most of publications. Publications were excluded, if formation of malignant tumour in the head and neck region interfered with implant or patient survival.

Publications were identified and abstracts were evaluated independently by two reviewers (FPS and AMSW) by formal consideration of inclusion criteria and due to content matching the search purposes. Agreement of inclusion or exclusion of publications by two reviewers was expressed by calculation of the $\kappa$-value. After reaching full consent between the reviewers regarding the screening of abstracts, publications were selected for inclusion into further analysis.

Data reporting on implant survival, patients and implants numbers and duration of observational periods were retrieved from included publications. Weighed mean values of age (patient-related) and of implantrelated implant survival rate (wmSR) and observational periods (mOP) were calculated.

For meta-analysis funnel and forest plots for all publications and for the subgroups of publications with data 
Table 1. MeSH and search term combinations of literature search utilizing electronic databases.

\begin{tabular}{|c|c|}
\hline $\begin{array}{l}\text { initial search to determine start } \\
\text { point of literature search }\end{array}$ & $\begin{array}{l}\text { (osseointegrated[All Fields] AND implant[All Fields]) AND ("survival"[All Fields] OR } \\
\text { "survival"[MeSH Terms]) AND (("1975/01/01"[PDAT] : "1990/12/31"[PDAT]) AND } \\
\text { "humans"[MeSH Terms]) }\end{array}$ \\
\hline pathologic condition & MeSH and search term combinations \\
\hline oLp & $\begin{array}{l}\text { ("lichen planus, oral"[MeSH Terms] OR ("lichen"[All Fields] AND "planus"[All Fields] AND } \\
\text { "oral"[All Fields]) OR "oral lichen planus"[All Fields] OR ("oral"[All Fields] AND "lichen"[All } \\
\text { Fields] AND "planus"[All Fields])) AND ("dental implants"[MeSH Terms] OR ("dental"[All } \\
\text { Fields] AND "implants"[All Fields]) OR "dental implants"[All Fields] OR ("dental"[All Fields] } \\
\text { AND "implant"[All Fields]) OR "dental implant"[All Fields]) }\end{array}$ \\
\hline $\mathrm{Pe}$ & $\begin{array}{l}\text { ("dental implants"[MeSH Terms] OR ("dental"[All Fields] AND "implants"[All Fields]) OR } \\
\text { "dental implants"[All Fields] OR ("dental"[All Fields] AND "implant"[All Fields]) OR "dental } \\
\text { implant"[All Fields]) AND ("pemphigus"[MeSH Terms] OR "pemphigus"[All Fields]) } \\
\text { ("dental implants"[MeSH Terms] OR ("dental"[All Fields] AND "implants"[All Fields]) OR } \\
\text { "dental implants"[All Fields] OR ("dental"[All Fields] AND "implant"[All Fields]) OR "dental } \\
\text { implant"[All Fields]) AND ("pemphigoid, bullous"[MeSH Terms] OR ("pemphigoid"[All Fields] } \\
\text { AND "bullous"[All Fields]) OR "bullous pemphigoid"[All Fields] OR "pemphigoid"[All Fields]) }\end{array}$ \\
\hline EB & $\begin{array}{l}\text { ("dental implants"[MeSH Terms] OR ("dental"[All Fields] AND "implants"[All Fields]) OR } \\
\text { "dental implants"[All Fields] OR ("dental"[All Fields] AND "implant"[All Fields]) OR "dental } \\
\text { implant"[All Fields]) AND ("epidermolysis bullosa"[MeSH Terms] OR ("epidermolysis"[All } \\
\text { Fields] AND "bullosa"[All Fields]) OR "epidermolysis bullosa"[All Fields]) }\end{array}$ \\
\hline $\mathrm{SjS}$ & $\begin{array}{l}\text { ("dental implants"[MeSH Terms] OR ("dental"[All Fields] AND "implants"[All Fields]) OR } \\
\text { "dental implants"[All Fields] OR ("dental"[All Fields] AND "implant"[All Fields]) OR "dental } \\
\text { implant"[All Fields]) AND Sjogren[All Fields] }\end{array}$ \\
\hline sLE & $\begin{array}{l}\text { "dental implants"[MeSH Terms] OR ("dental"[All Fields] AND "implants"[All Fields]) OR "dental } \\
\text { implants"[All Fields] OR ("dental"[All Fields] AND "implant"[All Fields]) OR "dental } \\
\text { implant"[All Fields]) AND (lupus erythemateux[All Fields] OR lupus erythemathosus[All Fields] } \\
\text { OR lupus erythematodes[All Fields] OR lupus erythematodus[All Fields] OR lupus } \\
\text { erythematoses[All Fields] OR lupus erythematosis[All Fields] OR lupus erythematosous[All } \\
\text { Fields] OR lupus erythematosus[All Fields] OR lupus erythematosus,[All Fields] OR lupus } \\
\text { erythematosys[All Fields] OR lupus erythematous[All Fields] OR lupus erythematousus[All } \\
\text { Fields]) }\end{array}$ \\
\hline $\mathrm{sSc}$ & $\begin{array}{l}\text { ("dental implants"[MeSH Terms] OR ("dental"[All Fields] AND "implants"[All Fields]) OR } \\
\text { "dental implants"[All Fields] OR ("dental"[All Fields] AND "implant"[All Fields]) OR "dental } \\
\text { implant"[All Fields]) AND ("scleroderma, systemic"[MeSH Terms] OR ("scleroderma"[All Fields] } \\
\text { AND "systemic"[All Fields]) OR "systemic scleroderma"[All Fields] OR "scleroderma"[All } \\
\text { Fields] OR "scleroderma, localized"[MeSH Terms] OR ("scleroderma"[All Fields] AND } \\
\text { "localized"[All Fields]) OR "localized scleroderma"[All Fields]) } \\
\text { ("dental implants"[MeSH Terms] OR ("dental"[All Fields] AND "implants"[All Fields]) OR } \\
\text { "dental implants"[All Fields] OR ("dental"[All Fields] AND "implant"[All Fields]) OR "dental } \\
\text { implant"[All Fields]) AND ("scleroderma, systemic"[MeSH Terms] OR ("scleroderma"[All Fields] } \\
\text { AND "systemic"[All Fields]) OR "systemic scleroderma"[All Fields] OR ("systemic"[All Fields] } \\
\text { AND "sclerosis"[All Fields]) OR "systemic sclerosis"[All Fields]) }\end{array}$ \\
\hline
\end{tabular}


regarding oLp, SjS, EB, and $\mathrm{sSc}$ were created. The funnel plot revealed that there is no evidence for publication bias if four publications were excluded from metaanalysis. Forest plots showed $95 \%$ confidence intervals for the pooled implant failure rate per year and for the failure rate of each study. Moreover, $\mathrm{I}^{2}$ (measure for het- erogeneity) was calculated for each meta-analysis.

The statistical analysis was carried out using SPSS 22.0, $\mathrm{R}$ version 3.4.3 and the $\mathrm{R}$ package "meta".

Table 2, 2 continue, 2 continue-1 contains the PRISMA checklist regarding the methodology of the systematic review process and data analyses.

Table 2. PRISMA checklist.

\begin{tabular}{|c|c|c|}
\hline Section / topic & checklist item & $\begin{array}{l}\text { reported on } \\
\text { page }\end{array}$ \\
\hline 1 title & $\begin{array}{l}\text { Implants in patients with oral manifestations of autoimmune or muco-cutaneous diseases } \\
\text { - a systematic review }\end{array}$ & 1 \\
\hline $\begin{array}{l}2 \text { abstract } \\
\text { structured } \\
\text { summary }\end{array}$ & $\begin{array}{l}\text { Aim: To give an overview on implant survival rates in patients with oral manifestations } \\
\text { of systemic autoimmune (oral Lichen planus (oLp), Pemphigus (Pe)), muco-cutaneous } \\
\text { (Epidermolysis bullosa (EB)), or autoimmune multisystemic rheumatic diseases (Sjögren's } \\
\text { syndrome (SjS), systemic Lupus erythemathosus (sLE), or systemic Sclerosis (sSc)). Mate- } \\
\text { rial and Methods: Systematic literature review (PubMed/Medline, Embase) using MESH } \\
\text { and search term combinations, published between } 1980 \text { and October } 2017 \text { in English or } \\
\text { German language reporting on dental implant-prosthetic rehabilitation of patients with } \\
\text { oLp, Pe, EB, SjS, sLE, sSc, study design, age, gender, follow-up period of or exceeding } 12 \\
\text { months and implant survival rate. Weighed mean values of implant survival rate (wmSR) } \\
\text { were calculated for patients with oLp, Pe, EB, SjS, sLE or sSc. Results: After a mean } \\
\text { follow-up period (mfp) of } 44.6 \text { months, a wmSR of } 98.3 \% \text { was calculated from data pub- } \\
\text { lished for patients with oLp (100 patients with } 302 \text { implants). Data of } 27 \text { patients (152 im- } \\
\text { plants) with EB revealed wmSR of } 98.7 \% \text { following mfp of } 32.6 \text { months. For } 71 \text { patients } \\
\text { (272 implants) with SjS, wmSR was } 94.2 \% \text { following a mfp of } 45.2 \text { months, and for } 6 \\
\text { patients ( } 44 \text { implants) with sSc, wmSR was } 97.7 \% \text { after mfp of } 37.5 \text { months. One case re- } \\
\text { port on one patient each with Pe (two implants) as well as sLE (6 implants) showed } 100 \% \\
\text { SR following at least } 24 \text { months. Summary: Implant survival rates of patients with oLp, } \\
\text { Pe, EB, SjS, sLE or sSc are comparable to those of healthy patients. For implant-prosthetic } \\
\text { rehabilitation of patients with Pe and sLE no conclusions can be drawn due to lack of suf- } \\
\text { ficient clinical data. Implant-prosthetic treatment guidelines regarding healthy patients } \\
\text { should be strictly followed, but frequent recall is recommended in patients affected with } \\
\text { oLp, SjS, EB, SSc, Pe or sLE. } \\
\text { Since the systematic review was not registered, no registration number is available. }\end{array}$ & 2 \\
\hline $\begin{array}{l}\text { introduction } \\
\text { rationale }\end{array}$ & $\begin{array}{l}\text { Since no guidelines regarding implant treatment of patients with oLp, Pe, EB, SjS, sLE } \\
\text { or sSc exist nor are contraindications defined, the aim of this systematic review of the } \\
\text { literature was to reveal, whether patients suffering from above mentioned diseases might } \\
\text { benefit from implant-prosthodontic rehabilitation. }\end{array}$ & 3 \\
\hline 4 objectives & $\begin{array}{l}\text { Which implant survival rates were reported in patients suffering from mucocutaneous or } \\
\text { autoinflammatory diseases oLp, Pe, EB, SjS, sLE or sSc? } \\
\text { PICO: patients suffering from oLp, Pe, EB, SjS, sLE or sSc (population); clinical use of } \\
\text { dental implant-prosthodontic rehabilitation (intervention); control groups were lacking; } \\
\text { implant survival rate (outcome) }\end{array}$ & 3,4 \\
\hline $\begin{array}{l}5 \text { methods } \\
\text { protocol and } \\
\text { registration }\end{array}$ & $\begin{array}{c}\text { A systematic literature search using MESH- and search term combinations (see Table 1) } \\
\text { was performed to identify publications meeting the inclusion criteria. } \\
\text { This systematic review was not registered in any database. }\end{array}$ & 4 \\
\hline $\begin{array}{l}6 \text { eligibility } \\
\text { criteria }\end{array}$ & $\begin{array}{l}\text { Inclusion of publications reporting on patients with oLp, Pe, EB, SjS, sLE or sSc (popula- } \\
\text { tion), undergoing clinical use of dental implant-prosthetic rehabilitation (intervention) and } \\
\text { revealing study design, age, gender, number of patients and implants, follow-up period of } \\
\text { or exceeding } 12 \text { months and implant survival rate (outcome); publication between } 1980 \\
\text { and October } 2017 \text { in English or German language; reporting on comparison of implant } \\
\text { survival rates between healthy and affected patients. } \\
\text { Exclusion of publications, if not meeting the inclusion criteria, or if formation of malig- } \\
\text { nant tumour in the head and neck region interfered with implant survival. } \\
\text { Since this systematic review was not registered in any database, the protocol is not avail- } \\
\text { able on a website. }\end{array}$ & 4 \\
\hline
\end{tabular}


Table 2 continue. PRISMA checklist.

\begin{tabular}{|c|c|c|}
\hline $\begin{array}{l}7 \text { information } \\
\text { sources }\end{array}$ & $\begin{array}{c}\text { Electronic literature databases (PubMed/Medline, Embase) were used exclusively. } \\
\text { Search period } 1980 \text { up to March } 2018 \text { (limit set by most recent available publication). Last } \\
\text { search date August } 2018 \text {. }\end{array}$ & 4 \\
\hline 8 search & See Table 1 & \\
\hline $\begin{array}{ll}9 & \text { study } \\
& \text { selection }\end{array}$ & $\begin{array}{c}\text { All publications identified with MESH- and search term combinations were screened } \\
\text { independently if meeting the scope and inclusion criteria and eligible publications were } \\
\text { further screened regarding the abstracts by two independent reviewers. Publications were } \\
\text { included into systematic review after full-text analysis, if all data required were provided. } \\
\text { Discrepancies between selected publications due to reviewers' choice were discussed and } \\
\text { full agreement was reached. See Figure } 1 .\end{array}$ & 4 \\
\hline $\begin{array}{l}10 \text { data } \\
\text { collection } \\
\text { process }\end{array}$ & $\begin{array}{l}\text { All data required were retrieved from publications into tables, considering pathologic } \\
\text { conditions oLp, Pe, EB, SjS, sLE, sSc. } \\
\text { Since data were provided within the publications, no contact to authors / investigators was } \\
\text { sought. }\end{array}$ & 4 \\
\hline 11 data items & $\begin{array}{l}\text { number of patients / implants, patients'age, gender, observational period, implant survival } \\
\text { rate }\end{array}$ & 4 \\
\hline $\begin{array}{l}12 \text { risk of bias } \\
\text { in individual } \\
\text { studies }\end{array}$ & $\begin{array}{l}\text { A quality assessment of the publications included for the systematic review following the } \\
\text { Cochrane collaboration recommendations for evaluation of RCTs (Higgins JPT, Green S. } \\
\text { Cochrane Handbook for Systematic Reviews of Interventions. 2011. Versión 5.1.0. http:// } \\
\text { handbook.cochrane.org/) was not applicable due to the entity of included publications } \\
\text { (especially the criteria random sequence generation and allocation concealment (both } \\
\text { accounting for selection bias), blinding of participants and personnel (performance bias), } \\
\text { blinding of outcome assessment (detection bias) were not applicable, since most publica- } \\
\text { tions were case reports or case series. Due to selective reporting within case reports, at- } \\
\text { trition bias (incomplete outcome data), reporting bias (selective reporting) were supposed } \\
\text { high. }\end{array}$ & 4 \\
\hline $\begin{array}{l}13 \text { summary } \\
\text { measures }\end{array}$ & $\begin{array}{l}\text { Weighed mean values of patient-related implant survival rate and observational periods } \\
\text { were calculated. }\end{array}$ & 4 \\
\hline $\begin{array}{l}14 \text { synthesis of } \\
\text { results }\end{array}$ & $\begin{array}{c}\text { Meta-analysis was calculated regarding incidence rate referring to mean number of im- } \\
\text { plant failures per year. }\end{array}$ & 4 \\
\hline $\begin{array}{l}15 \text { risk of bias } \\
\text { across } \\
\text { studies }\end{array}$ & $\begin{array}{l}\text { Due to the publications' entities (most of them were case reports, only two studies pro- } \\
\text { vided with a control group of healthy patients), the risk of bias was considered high. } \\
\text { Funnel plot analysis detected four studies with extremely outlying data, which were ex- } \\
\text { cluded from meta-analysis. }\end{array}$ & 4 \\
\hline $\begin{array}{c}16 \text { additional } \\
\text { analyses }\end{array}$ & $\begin{array}{l}\text { Comparison of survival rates were performed utilizing t-test following confirmation of } \\
\text { normal distribution (Kolmogorov-Smirnow-test) for patients with oLp. }\end{array}$ & $5-6$ \\
\hline $\begin{array}{l}17 \text { results } \\
\text { study } \\
\text { selection }\end{array}$ & $\begin{array}{l}\text { Numbers of studies identified for each pathologic condition and numbers of studies in- } \\
\text { cluded are reported within the text. }\end{array}$ & $5-6$ \\
\hline $\begin{array}{l}18 \text { study } \\
\text { characteristics }\end{array}$ & See Table 3 sections a-d & $5-6$ \\
\hline $\begin{array}{l}19 \text { risk of bias } \\
\text { within studies }\end{array}$ & $\begin{array}{l}\text { Funnel plot analysis revealed four studies with extremely outlying data, which were ex- } \\
\text { cluded from further meta-analysis (figures } 2 \mathrm{a} \text { and } \mathrm{b} \text { ). }\end{array}$ & 7 \\
\hline $\begin{array}{c}20 \text { results of } \\
\text { individual } \\
\text { studies }\end{array}$ & See table 3 , sections a-d. & $5-6$ \\
\hline $\begin{array}{l}21 \text { synthesis of } \\
\text { results }\end{array}$ & See Figures 3a-d. & 7 \\
\hline $\begin{array}{l}22 \text { risk of bias } \\
\text { across studies }\end{array}$ & See figures $2 a-b$. & 7 \\
\hline
\end{tabular}


Table 2 continue-1. PRISMA checklist.

\begin{tabular}{|c|c|c|}
\hline $\begin{array}{l}23 \text { additional } \\
\text { analysis }\end{array}$ & See Table 3. & $5-6$ \\
\hline $\begin{array}{l}24 \text { summary of } \\
\text { evidence }\end{array}$ & $\begin{array}{l}\text { On basis of weak-evidence publications with a high risk of bias, implant survival rates } \\
\text { of patients with oLp, Pe, EB, SjS, sLE or sSc are comparable to those of healthy patients. } \\
\text { Mean follow-up periods were exceeding } 32 \text { months. } \\
\text { Further case studies or prospective studies should report outcomes following longer ob- } \\
\text { servation periods with consideration of course of the diseases. Multicentric data analyses } \\
\text { might be a viable method to gain more data regarding the above mentioned diseases, since } \\
\text { the prevalence of the diseases is low. }\end{array}$ & 11 \\
\hline 25 limitations & $\begin{array}{c}\text { Since most of included publications were low-level evidence case reports or case series, } \\
\text { and mean follow-up was calculated between } 32 \text { and } 45 \text { months, conclusions can be drawn } \\
\text { on a very limited evidence-level. Risk of attrition bias and reporting bias are supposed } \\
\text { high. }\end{array}$ & \\
\hline 26 conclusions & $\begin{array}{l}\text { Within the limits of low-level evidence publications analysed and limited mean observa- } \\
\text { tional periods, implant-prosthetic treatment of patients with oLp, Pe, EB, or SjS seems } \\
\text { to be a promising treatment option. For implant-prosthetic rehabilitation of patients with } \\
\text { Pe and sLE no conclusions can be drawn due to lack of sufficient clinical data. However, } \\
\text { treatment guidelines regarding healthy patients should be strictly followed. Moreover, } \\
\text { frequent recall is recommended in patients affected with oLp, SjS, EB, SSc, Pe or sLE. }\end{array}$ & 11 \\
\hline 27 funding & $\begin{array}{l}\text { No funding nor other financial nor other support was received by any author with regard to } \\
\text { this systematic review. All authors declare no conflict of interests. }\end{array}$ & 1 \\
\hline
\end{tabular}

\section{Results}

Figure 1 displays search results, identification, screening for eligibility and inclusion of publications considered for systematic review and meta-analysis. Comparison of inclusion of publications considering abstract analysis revealed a kappa-value of $0.932(p<0.0001)$. Disagreement regarding inclusion of two and exclusion of one publications was resolved after full text analysis, finally reaching full agreement.

The risk of bias assessment of included publications revealed an overall high risk of attrition bias and reporting bias, since case reports and case studies were included mainly. Assessment of random sequence generation, allocation concealment, blinding of participants as well as outcome assessment (accounting for selection bias, performance bias and detection bias) was not applicable. Data were retrieved from included publications and information on reference, study type, number of implants and patients and their age, duration of follow-up period as well as implant survival rates are listed in Table 3, 3 continue sections a to $\mathrm{d}$.

-Oral Lichen planus

Nine out of 32 publications identified within databases met the inclusion criteria (four case reports, three retrospective studies, one prospective study, and one prospective controlled study). Data of 73 female and 27 male patients suffering from oLp were retrieved from these nine publications (see Table 3 section a). From the case report by Reichart (6) one patient was discarded due to unknown duration of follow-up period.

Despite lack of details regarding prosthodontic treatment for patient- or implant-based analysis in some publications (information on $38 \%$ of patients as well as $37.8 \%$ of implants were not available), the majority of patients (90.3\%) and implants (91.6\%) respectively were treated with fixed partial dentures, whereas only a few removable complete prostheses $(1.6 \%$ by patientrelated and $2.1 \%$ by implant-related analysis) and fixed complete prostheses $(8.1 \%$ by patient-related and $6.3 \%$ by implant-related analysis) were used.

In one study, 55 implants were inserted during acute flare of active oLp using immediate implantation into the socket subsequently following extraction (17 implants) or immediate loading mode (31 implants), or both conditions (9 implants). 42 implants failed ( $24 \mathrm{im}$ mediately loaded, 6 immediately inserted) and were removed and replaced after oral corticosteroid therapy. None of the replaced implants failed (10).

In the study by Anitua et al. (11), short implants up to $8.5 \mathrm{~mm}$ in length were used exclusively in 8 patients with erosive and 15 patients with reticular oLp.

-Sjögren's Syndrome

Nine publications of 13 identified within the databases met the inclusion criteria for the systematic review and revealed data of 65 female as well as 6 male patients suffering from $\mathrm{SjS}$, receiving implant-prosthetic rehabilitation (six case reports and one case series, retrospective and prospective study, each, see Table 3 section b). Data regarding distribution of type of prosthesis were available related to jaw (maxilla and or mandible) only. 92 jaws were treated. Of these, $44.6 \%$ were treated using implant-retained removable complete dentures (overdentures). While counting implant-fixed single crowns $(29.3 \%)$ and fixed partial dentures $(7.6 \%)$ for 


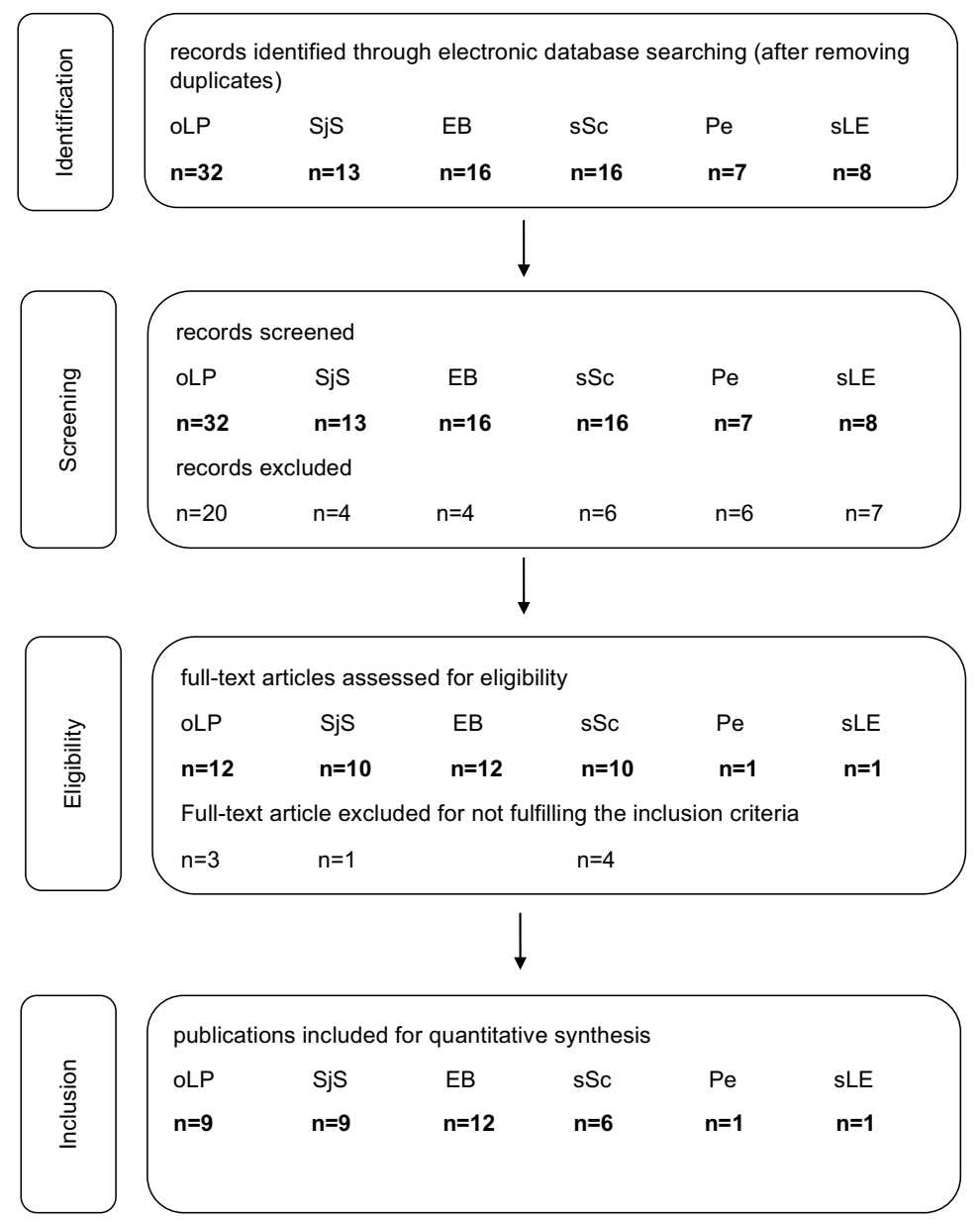

Fig. 1. Search results, identification, screening for eligibility and inclusion of publications considered for systematic review and meta-analysis.

fixed partial restorations (36.9\%) and counting $18.5 \%$ fixed complete dentures, more jaws were treated using fixed restorations on implants (55.4\%) compared to removable prostheses.

-Epidermolysis bullosa

Data from 12 publications regarding implant-prosthetic rehabilitation of 27 patients (10 male and 17 female patients) with $\mathrm{EB}$, receiving 152 implants were analysed (see Table 3, 3 continue section c). From the case series by Peñarrocha $e t$ al. (23) three patients with 27 implants were discarded since these were also subject of another publication (22).

Analysis by jaw $(n=41)$ revealed, that the majority of jaws were treated with implant-fixed complete dentures (70.7 \%), whereas $22 \%$ of jaws were treated with implant-retained removable complete dentures and $7.3 \%$ with implant-fixed partial dentures.

-Systemic Sclerosis

Six publications out of 16 matching the search term combinations met the inclusion criteria, reported on treatment courses of one male and five female patients with $\mathrm{sSc}$ undergoing implant-prosthodontic rehabilitation (data listed in Table 3, 3 continue section d).
Analysis per jaw revealed the use of four implant-fixed complete dentures, two implant-borne bar-retained removable complete dentures and three implant-fixed partial dentures (two were integrated in one maxilla). -Pemphigus and systemic Lupus erythematosus Of seven publications on $\mathrm{Pe}$ and eight publications on sLE identified, one publication was included each, reporting on one female patient (70 years old) suffering from Pe (2 implants, ball-attachment-retained mandibular overdenture, 32 months observational period) (36) and one female patient with sLE (49 years old, 6 implants, single fixed crowns, 24 months observational period) (37), both with $100 \%$ implant survival.

-Meta-analyses

Meta-analysis was carried out, calculating a funnel plot to detect publication bias.

The funnel plot for all publications indicated that four publications (3,10 [including results prior to corticosteroid therapy in "active" oLP only],11,13) had to be excluded because their rate estimates for implant failure were too extreme (outliers) (see Figure 2a). Figure $2 b$ shows the funnel plot, showing no asymmetry, revealing no evidence for further bias after removing the four 
Table 3. Study type, demographic data, duration of observation periods and implant survival rate of patients with oLp (section a), SjS (section b), EB (section c), sSc (section d).

\begin{tabular}{|c|c|c|c|c|c|c|}
\hline Study & $\begin{array}{l}\text { study } \\
\text { type }\end{array}$ & $\begin{array}{c}\text { number of } \\
\text { patients }\end{array}$ & $\begin{array}{l}\text { number of } \\
\text { implants }\end{array}$ & $\begin{array}{l}\text { age / mean age } \\
\text { (years) }\end{array}$ & $\begin{array}{c}\text { follow-up / } \\
\text { mean follow-up } \\
\text { (months) }\end{array}$ & $\begin{array}{c}\text { implant survival } \\
\text { rate } \\
(\%)\end{array}$ \\
\hline \multicolumn{7}{|l|}{ section a oLp } \\
\hline Esposito et al. 2000 (3) & $\mathrm{cr}$ & 1 & 2 & 69 & 32,60 & 0 \\
\hline Esposito et al. 2003 (4) & cr & 2 & 4 & 72,78 & 21 & 100 \\
\hline Öczakir et al. 2005 (5) & cr & 1 & 4 & 74 & 72 & 100 \\
\hline Reichart 2006 (6) & cr & 2 & 5 & 63,68 & 36,156 & 100 \\
\hline Hernandez et al. 2012 (7) & $\mathrm{pc}$ & 18 & 56 & 53.7 & 56.5 & 100 \\
\hline Czerninsky et al. 2013 (8) & $\mathrm{r}$ & 14 & 54 & 59 & 12 & 100 \\
\hline Lopez-Jornet et al. 2014 (9) & $\mathrm{r}$ & 16 & 56 & 64.5 & 42 & 96.4 \\
\hline Aboushelib et al. 2017 (10) & $\mathrm{p}$ & 23 & $\begin{array}{c}55 \\
142^{*}\end{array}$ & 56.7 & $\begin{array}{c}2.8 \\
136^{*}\end{array}$ & $\begin{array}{c}13.0 \\
/ 100 *\end{array}$ \\
\hline Anitua et al. 2018 (11) & $\mathrm{r}$ & 23 & 66 & 58 & 68 & 98.5 \\
\hline $\begin{array}{l}\text { total } \\
\text { weighed mean }\end{array}$ & & 100 & 302 & $58.9 \pm 5.6$ & $\begin{array}{l}40.9 \pm 24.7 \\
* 44.6 \pm 21.4\end{array}$ & $\begin{array}{l}84.4 \pm 35.0 \\
/ * 98.3 \pm 8.2\end{array}$ \\
\hline remarks & \multicolumn{6}{|c|}{ *calculated considering the results following corticosteroid therapy (10) } \\
\hline \multicolumn{7}{|l|}{ section b $\mathrm{SjS}$} \\
\hline Payne et al. 1997 (12) & $\mathrm{cr}$ & 3 & 26 & $38,38,40$ & $96,36,18$ & 88.5 \\
\hline Isidor et al. 1999 (13) & $\mathrm{p}$ & 8 & 54 & $53-70$ & 48 & 87 \\
\hline Binon 2005 (14) & $\mathrm{cr}$ & 1 & 6 & 67 & 156 & 100 \\
\hline Öczakir et al. 2005 (5) & $\mathrm{cr}$ & 2 & 12 & 63,64 & 24,60 & 100 \\
\hline Weinländer et al. 2010 (15) & cs & 4 & 21 & 55.6 & $42,46,48,91$ & 100 \\
\hline Spinato et al. 2010 (16) & $\mathrm{cr}$ & 1 & 6 & 62 & 22 & 100 \\
\hline $\begin{array}{l}\text { de Mendonça Invernici et } \\
\text { al. } 2014 \text { (17) }\end{array}$ & $\mathrm{cr}$ & 1 & 2 & 58 & 72 & 100 \\
\hline Korfage et al. 2016 (18) & $\mathrm{r}$ & 50 & 140 & 67 & 42 & 97.1 \\
\hline Peron et al. 2017 (19) & $\mathrm{cr}$ & 1 & 5 & 62 & 36 & 100 \\
\hline $\begin{array}{l}\text { total } \\
\text { weighed mean }\end{array}$ & & 71 & 272 & $64.2 \pm 6.9$ & $45.2 \pm 23.8$ & $94.2 \pm 23.4$ \\
\hline \multicolumn{7}{|l|}{ section c EB } \\
\hline $\begin{array}{l}\text { Peñarrocha-Diago et al. } \\
2000(20)\end{array}$ & $\mathrm{cr}$ & 4 & 15 & $35,30,26,30$ & $12,24,36,48$ & 100 \\
\hline Lee et al. 2007 (21) & $\mathrm{cr}$ & 1 & 8 & 29 & 23 & 100 \\
\hline Peñarrocha et al. 2007a (22) & $\mathrm{cr}$ & 3 & 27 & $44,29,43$ & $60,36,12$ & 96.2 \\
\hline $\begin{array}{l}\text { Peñarrocha et al. } 2007 \mathrm{~b} \\
\text { (23) }\end{array}$ & cs & 3 & 11 & $\begin{array}{c}23,36,28,44 \\
29,43\end{array}$ & $\begin{array}{c}108,96,84,60 \\
36,12\end{array}$ & 97.4 \\
\hline $\begin{array}{l}\text { Larrazabal-Moron et al. } \\
2009 \text { (24) }\end{array}$ & $\mathrm{cr}$ & 1 & 2 & 52 & 18 & 100 \\
\hline Oliveira et al. 2010 (25) & $\mathrm{cr}$ & 1 & 2 & 13 & 48 & 100 \\
\hline Müller et al. 2010 (26) & $\mathrm{cr}$ & 1 & 10 & $>20$ & 48 & 100 \\
\hline
\end{tabular}


Table 3 continue. Study type, demographic data, duration of observation periods and implant survival rate of patients with oLp (section a), SjS (section b), EB (section c), sSc (section d)

\begin{tabular}{|c|c|c|c|c|c|c|}
\hline $\begin{array}{l}\text { Peñarrocha-Oltra et al. } 2011 \\
\text { (27) }\end{array}$ & cs & 6 & 32 & $\begin{array}{c}24,34,55,51 \\
33,27\end{array}$ & $\begin{array}{c}24,36,12,24 \\
12,48\end{array}$ & 100 \\
\hline $\begin{array}{l}\text { Peñarrocha-Oltra et al. } \\
2012(28)\end{array}$ & cs & 4 & 23 & $27,55,51,44$ & $24,12,48,24$ & 100 \\
\hline $\begin{array}{l}\text { Augustin-Panadero et al. } \\
2015 \text { (29) }\end{array}$ & $\mathrm{cr}$ & 1 & 8 & 19 & 18 & 87.5 \\
\hline $\begin{array}{l}\text { Augustin-Panadero et al. } \\
2017 \text { (30) }\end{array}$ & $\mathrm{cr}$ & 1 & 6 & 52 & 30.7 & 100 \\
\hline Alikhasi et al. 2017 (31) & $\mathrm{cr}$ & 1 & 8 & 36 & 18 & 100 \\
\hline $\begin{array}{l}\text { total } \\
\text { weighed mean }\end{array}$ & & 27 & 152 & $35.4 \pm 11.6$ & $32.6 \pm 22.2$ & $98.7 \pm 11.3$ \\
\hline \multicolumn{7}{|l|}{ section d sSc } \\
\hline $\begin{array}{l}\text { Jensen \& Sindet-Pedersen } \\
1990(32)\end{array}$ & $\mathrm{cr}$ & 1 & 9 & 39 & 24 & 88.9 \\
\hline Raviv et al. 1996 (33) & $\mathrm{cr}$ & 1 & 3 & 65 & 28 & 100 \\
\hline Öczakir et al. 2005 (5) & $\mathrm{cr}$ & 1 & 8 & 64 & 60 & 100 \\
\hline Weinländer et al. 2010 (15) & $\mathrm{cr}$ & 1 & 6 & 55.6 & 46 & 100 \\
\hline Zigdon et al. 2011 (34) & $\mathrm{cr}$ & 1 & 12 & 45 & 36 & 100 \\
\hline Baptist 2016 (35) & $\mathrm{cr}$ & 1 & 6 & 61 & 30 & 100 \\
\hline $\begin{array}{l}\text { total } \\
\text { weighed mean }\end{array}$ & & 6 & 44 & $54.9 \pm 10.7$ & $37.5 \pm 13.4$ & $97.7 \pm 15.1$ \\
\hline
\end{tabular}

(cr case report, cs case series, $\mathrm{p}$ prospective study, pc prospective controlled study, $\mathrm{r}$ retrospective study).
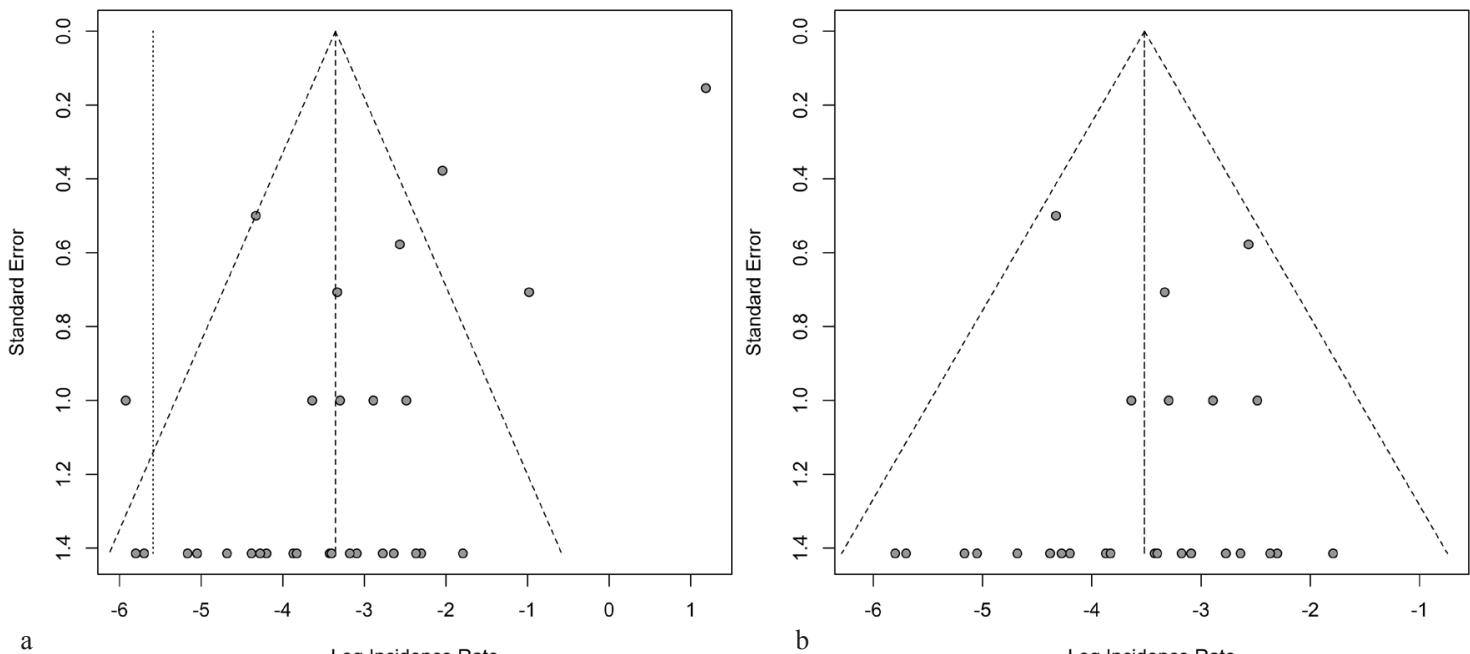

Fig. 2. a) Funnel plot for all publications. Four publications (3,10 [including results prior to corticosteroid therapy in "active" oLP only],11,13) were found to reveal too extreme rate estimates for implant failure. b) Funnel plot for all publications following exclusion of outliers $(3,10$ [including results prior to corticosteroid therapy in "active" oLP only],11,13), revealing no risk of bias.

publications as indicated. Thus, the remaining publications were included into further meta-analysis.

Figure 3 shows the forest plot for all included publications $(\mathrm{n}=35)$ on oLp, $\mathrm{SjS}, \mathrm{EB}, \mathrm{sSc}, \mathrm{Pe}$, and sLe revealing a considerably low incidence rate referring to mean number of implant failures per year of 0.0297 (fixed effect model). Figures 3a-d show forest plots for data, retrieved from publications on oLp, SjS, EB, and sSc, exclusively. 


\begin{tabular}{|c|c|c|c|c|c|c|c|c|}
\hline Study & Events & Time & Incidence Rate & & Rate & $95 \%-\mathrm{Cl}$ & $\begin{array}{r}\text { Weight } \\
\text { (fixed) }\end{array}$ & $\begin{array}{r}\text { Weight } \\
\text { (random) }\end{array}$ \\
\hline Esposito et al. 2003 & 0 & 7.0000 & 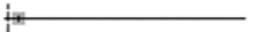 & & 0.0714 & {$[0.0045 ; 1.1420]$} & $10.0 \%$ & $10.6 \%$ \\
\hline Oczakir et al. 2005 & 0 & 24.0000 & the & & 0.0208 & {$[0.0013 ; 0.3331]$} & $10.0 \%$ & $10.6 \%$ \\
\hline Reichart 2006 & 0 & 5.0000 & + & & 0.1000 & {$[0.0063 ; 1.5988]$} & $10.0 \%$ & $10.6 \%$ \\
\hline Hernandez et al. 2012 & 0 & 149.3333 & & & 0.0033 & {$[0.0002 ; 0.0535]$} & $10.0 \%$ & $10.6 \%$ \\
\hline Czerninski et al. 2013 & 0 & 54.0000 & $i$ & & 0.0093 & {$[0.0006 ; 0.1480]$} & $10.0 \%$ & $10.6 \%$ \\
\hline Lopez-Jornet et al. 2014 & 2 & 56.0000 & $\div$ & & 0.0357 & {$[0.0089 ; 0.1428]$} & $40.0 \%$ & $36.6 \%$ \\
\hline Aboushelib et al. 2017b* & & 165.0000 & & & 0.0030 & {$[0.0002 ; 0.0484]$} & $10.0 \%$ & $10.6 \%$ \\
\hline \multirow{2}{*}{\multicolumn{3}{|c|}{$\begin{array}{l}\text { Fixed effect model } \\
\text { Random effects model }\end{array}$}} & $\phi$ & & \multirow{4}{*}{\multicolumn{2}{|c|}{$\begin{array}{l}0.0217[0.0090 ; 0.0520] \\
0.0211[0.0084 ; 0.0531]\end{array}$}} & $100.0 \%$ & - \\
\hline & & & $\dot{0}$ & & & & - & $100.0 \%$ \\
\hline \multirow{2}{*}{\multicolumn{5}{|c|}{ Heterogeneity: $I^{2}=6.6 \%[0.0 \% ; 72.7 \%], \tau^{2}=0.1080, p=0.38$}} & & & & \\
\hline & & & & & & & & \\
\hline
\end{tabular}

\begin{tabular}{|c|c|c|c|c|c|c|c|}
\hline Study & Events & Time & Incidence Rate & Rate & $95 \%-\mathrm{Cl}$ & $\begin{array}{r}\text { Weight } \\
\text { (fixed) }\end{array}$ & $\begin{array}{r}\text { Weight } \\
\text { (random) }\end{array}$ \\
\hline Payne et al. 1997 & 3 & 39.0000 & + & 0.0769 & {$[0.0248 ; 0.2385]$} & $30.0 \%$ & $28.6 \%$ \\
\hline Binon 2005 & 0 & 78.0000 i & & 0.0064 & {$[0.0004 ; 0.1025]$} & $5.0 \%$ & $6.0 \%$ \\
\hline Oczakir et al. 2005 & 0 & 24.0000 & & 0.0208 & {$[0.0013 ; 0.3331]$} & $5.0 \%$ & $6.0 \%$ \\
\hline Weinländer et al. 2010 & 0 & 87.5000 . & & 0.0057 & {$[0.0004 ; 0.0914]$} & $5.0 \%$ & $6.0 \%$ \\
\hline Spinato et al. 2010 & 0 & 11.0000 & & 0.0455 & {$[0.0028 ; 0.7267]$} & $5.0 \%$ & $6.0 \%$ \\
\hline de Mendonca et al. 2014 & 0 & 12.0000 & & 0.0417 & {$[0.0026 ; 0.6661]$} & $5.0 \%$ & $6.0 \%$ \\
\hline Korfage et al. 2016 & 4 & 303.3333 & & 0.0132 & {$[0.0049 ; 0.0351]$} & $40.0 \%$ & $35.3 \%$ \\
\hline Peron et al. 2017 & 0 & 15.0000 & & 0.0333 & {$[0.0021 ; 0.5329]$} & $5.0 \%$ & $6.0 \%$ \\
\hline \multirow{2}{*}{\multicolumn{4}{|c|}{$\begin{array}{l}\text { Fixed effect model } \\
\text { Random effects model }\end{array}$}} & \multirow{2}{*}{\multicolumn{2}{|c|}{$\begin{array}{l}0.0250[0.0135 ; 0.0465] \\
0.0250[0.0124 ; 0.0502]\end{array}$}} & $100.0 \%$ & \\
\hline & & & & & & - & $100.0 \%$ \\
\hline
\end{tabular}

$\begin{array}{lllllll}0.1 & 0.2 & 0.3 & 0.4 & 0.5 & 0.6 & 0.7\end{array}$

\begin{tabular}{|c|c|c|c|c|c|c|c|c|c|}
\hline Study & Events & Time & & Incidence Rate & & Rate & $95 \%-\mathrm{Cl}$ & $\begin{array}{r}\text { Weight } \\
\text { (fixed) }\end{array}$ & $\begin{array}{r}\text { Weight } \\
\text { (random) }\end{array}$ \\
\hline Penarrocha-Diago et al. 2000 & & $15.0000 \div$ & & & & 0.0333 & {$[0.0021 ; 0.5329]$} & $6.7 \%$ & $6.7 \%$ \\
\hline Lee et al. 2007 & & $15.3333+$ & & & & 0.0326 & {$[0.0020 ; 0.5213]$} & $6.7 \%$ & $6.7 \%$ \\
\hline Penarrocha et al. 2007a & 1 & $27.0000 \div$ & & & & 0.0370 & {$[0.0052 ; 0.2629]$} & $13.3 \%$ & $13.3 \%$ \\
\hline Penarrocha et al. 2007b & & $38.0000 \div$ & & & & 0.0263 & {$[0.0037 ; 0.1868]$} & $13.3 \%$ & $13.3 \%$ \\
\hline Larrazabal-Moron et al. 2009 & 0 & 3.0000 & & & & 0.1667 & {$[0.0104 ; 2.6646]$} & $6.7 \%$ & $6.7 \%$ \\
\hline Oliveira et al. 2010 & 0 & $5.0000 \div$ & & & & 0.1000 & {$[0.0063 ; 1.5988]$} & $6.7 \%$ & $6.7 \%$ \\
\hline Müller et al. 2010 & & 33.3333 & & & & 0.0150 & {$[0.0009 ; 0.2398]$} & $6.7 \%$ & $6.7 \%$ \\
\hline Penarrocha-Oltra et al. 2011 & 0 & $36.0000 \div$ & & & & 0.0139 & {$[0.0009 ; 0.2220]$} & $6.7 \%$ & $6.7 \%$ \\
\hline Penarrocha-Oltra et al. 2012 & 0 & $23.0000 \div$ & & & & 0.0217 & {$[0.0014 ; 0.3476]$} & $6.7 \%$ & $6.7 \%$ \\
\hline Augustin-Panadero et al. 2015 & 1 & $12.0000+$ & & & & 0.0833 & {$[0.0117 ; 0.5916]$} & $13.3 \%$ & $13.3 \%$ \\
\hline Augustin-Panadero et al. 2017 & 0 & $8.0000 \div$ & & & & 0.0625 & {$[0.0039 ; 0.9992]$} & $6.7 \%$ & $6.7 \%$ \\
\hline Alikhasi et al. 2017 & 0 & 12.0000 & & & & 0.0417 & {$[0.0026 ; 0.6661]$} & $6.7 \%$ & $6.7 \%$ \\
\hline Fixed effect model & & 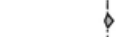 & & & & 0.0407 & {$[0.0199 ; 0.0833]$} & $100.0 \%$ & $r$ \\
\hline Random effects model & & 0 & & & & 0.0407 & {$[0.0199 ; 0.0833]$} & - & $100.0 \%$ \\
\hline \multirow{2}{*}{\multicolumn{3}{|c|}{ Heterogeneity: $I^{2}=0.0 \%[0.0 \% ; 0.0 \%], \tau^{2}=0, p=0.98$}} & 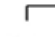 & 1 & ᄀ & & & & \\
\hline & & & 0.5 & 1.5 & 2.5 & & & & \\
\hline
\end{tabular}

d

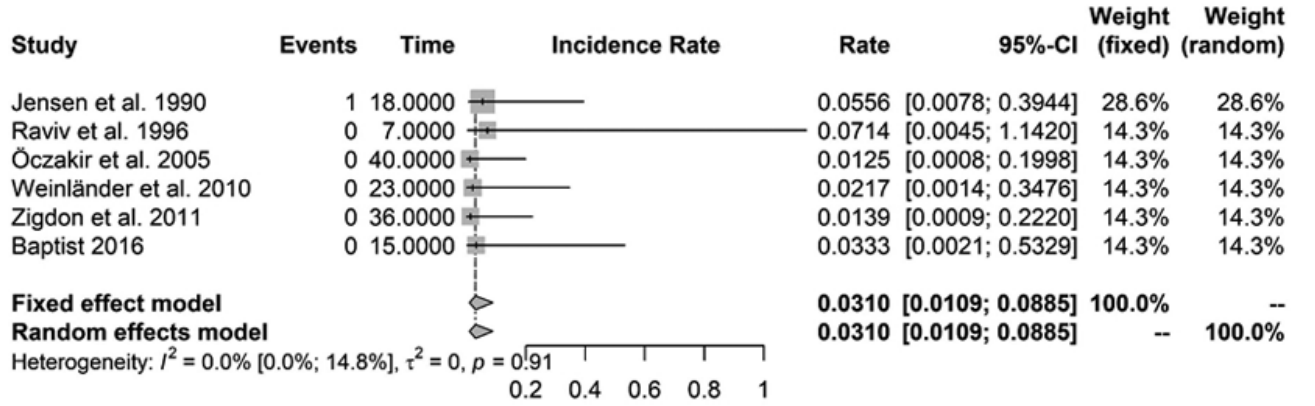

Fig. 3. a) Forest plot for 7 publications on oLp. Incidence rate of mean number of implant failures per year: 0.0217 (CI95\%: 0.0090; 0.0520, fixed effect model), no significant heterogeneity: $\left.\mathrm{I}^{2}=6.6 \%(\mathrm{CI} 95 \%: 0.0 \% ; 72.7 \%) ; p=0.38 . \mathrm{b}\right)$ Forest plot for 8 publications on $\mathrm{SjS}$. Incidence rate of mean number of implant failures per year: 0.0250 (CI95\%: 0.0135 ; 0.0465, fixed effect model), no significant heterogeneity: $\mathrm{I}^{2}=10.4 \%$ (CI95\%: $0.0 \% ; 70.9 \%$ ); $p=0.35$. c) Forest plot for 12 publications on EB. Incidence rate of mean number of implant failures per year: 0.0407 (CI95\%: 0.0199; 0.0833, fixed effect model), no significant heterogeneity: $\mathrm{I}^{2}=0.0 \%$ (CI95\%: $0.0 \% ; 0.0 \%$ ); $p=0.98$. d) Forest plot for 6 publications on sSc. Incidence rate of mean number of implant failures per year: 0.0310 (CI95\%: 0.0109; 0.0885, fixed effect model), no significant heterogeneity: $\mathrm{I}^{2}=0.0 \%$ (CI95\%: $\left.0.0 \% ; 14.8 \%\right) ; p=0.91$. 
Furthermore, measures for heterogeneity $\mathrm{I}^{2}$ for all included studies and for the subgroups regarding oLp, SjS, EB, sSc, Pe, and sLe were calculated. In all instances $\mathrm{I}^{2}$ was small and not significantly different from zero.

\section{Discussion}

Gingiva and other oral tissues may exhibit several pathologic phenomena as symptoms or manifestations of systemic diseases, requiring further diagnostic and interdisciplinary treatment (38). Although epidemiological data indicate low prevalence with regional variations for oLp (1 - $2 \%$ (39)), $\mathrm{SjS}(0.5-1 \%$ (40)), and sLe $(0.05 \%$ (41)), or rare prevalence for EB (up to 0.001 $\%$ (42)), sSc (up to $0.03 \%$ (43)), and Pe (0.05\% (44)), these patients affected require dental treatment, including prosthetic rehabilitation. Oral conditions in autoinflammatory, autoimmune, rheumatic or muco-cutaneous diseases require special care due to oral lesions (ulcer- or blister formation, enhanced risk for malignant tumours), sicca symptoms, scar tissue formation, limited mouth opening, and due to side effects of antiinflammatory, immune-modulating medication. Consequently, quality of life of these patients is reduced. Burden related to disease as well as adverse effects of medications is high for the patients, challenging the dental professional due to limited treatment options regarding conventional prosthodontic therapy. Especially wearing mucosal-borne removable partial or complete prostheses is impeded if not impossible.

Decision-making for dental implant-retained or fixed prosthodontic devices in order to improve speaking, swallowing, chewing, quality of life (45) should consider a critical weighing of advantages and risks, comorbidities as well as disease-related medication adverse effects, possibly interacting with osseointegration and implant prognosis. Generally, in patients affected by conditions and diseases mentioned above, large-area contact between oral mucosa and artificial surface of prosthodontic device and retention of the total or partial denture, or reduction of contact area between prostheses and mucosa is pursued.

The numbers of publications regarding implant-prosthodontic treatment under the above mentioned conditions and pathoses are low in general. The evidence-level of 38 publications included into this systematic review was limited (among them 26 case reports, four case series, four retrospective studies, two prospective studies, one prospective controlled study). Therefore, decision making prior to any intervention is based on low level of external evidence, but should include knowledge, experience and internal evidence of the dentist as well as thorough analysis of any conditions of the individual patient to evaluate risks and expected benefit and to provide a thorough patient information. Interdisciplinary consultations are required. Status of disease progress and overall prognosis should be considered additionally.
-Oral Lichen planus

oLp is a chronic autoimmune and inflammatory disease and may manifest as asymptomatic or symptomatic. About 1/3 of affected patients reveal gingival manifestations. Patients complain about mucosal burning sensations or pain caused by epithelial desquamation, erosions and ulcerations. Therefore, any contact or friction between dentures and mucosa should be avoided or reduced.

Data analysis of 100 patients included into this systematic review showed, that implant-fixed partial as well as complete prostheses were utilized mainly for prosthodontic rehabilitation of patients suffering from oLp. Implant-retained removable complete dentures were used in only $1.6 \%$ of patients. Considering those patients with active oLp and replacement of failed implants following systemic corticosteroid therapy in one study (10), weighed mean implant survival rate was calculated $98 \%$ after a mean follow-up period of 44.6 months, which is comparable to data from healthy patients.

Implants in patients with erosive oLp revealed no significant reduction of survival in some publications $(4,6-$ 9,11), whereas Aboushelib et al. (10) reported a significant effect of "active" oLp on implant loss, especially for those immediately loaded. Following oral corticosteroid and local soft laser therapy and recovery, implant replacement was performed and no further implant failures were observed. Therefore, to prevent disturbance of wound healing or osseointegration it is recommended to omit any surgical intervention during active, erosive phases of oLp $(3,6-8,10)$. Additionally, local treatment of erosions and ulcerations with clobetasoldipropionate is recommended (7). Strict patient adherence to regular and frequent follow-up appointments and oral hygiene instructions should be asserted not only to rule out inflammatory tissue response interfering with long-term survival of implants (peri-implant mucositis and periimplantitis) (1), but also to early detect malignant transformation of oLp into OSCC.

-Sjögren's Syndrome

Treatment courses of 71 patients suffering from $\mathrm{SjS}$ with a weighed mean age 64 years were published - female patients were treated predominantly. Within this systematic review, the weighed mean survival of implants of $94 \%$ after a mean follow-up of 45 months was found slightly less regarding other autoimmune diseases considered within this systematic review.

$\mathrm{SjS}$ is a chronic systemic autoimmune disease. Due to affection of exocrine glands - salivary and lacrimal glands in particular - patients suffer from hyposalivation and xerophthalmia, resulting - among other burdens - in stomatitis sicca, xerostomia, burning sensations, and difficulties to swallow.

Prosthodontic rehabilitation - especially using mucosal- 
borne dentures - is impeded due to dryness of oral mucosa, causing mucosal sensations, pain, or ulcerations. However, within the cohort of published treatment courses included into this systematic review, nearly half of the jaws $(44.6 \%)$ were treated using implant-retained removable complete dentures, whereas $55.4 \%$ of the jaws were treated with implant-fixed prosthodontic restorations.

Although biofilm accumulation with concomitant enhanced risk of peri-implant mucositis or peri-implantitis is suspected due to hyposalivation, relatively high mean weighed implant survival rate was found in patients with $\mathrm{SjS}$.

Patients with secondary SjS and rheumatoid arthritis sometimes may reveal limited manual abilities to perform proper oral hygiene. This and possible necessity of anti-inflammatory as well as immunosuppressive medication possibly interfering not only with osseointegration but health of peri-implant tissue should be considered while risk-benefit assessment, in therapy planning and thorough patient information as well. Patients should follow regular and frequent recall to early detect peri-implant mucositis and indicators for oral hygiene deficit.

-Epidermolysis bullosa

EB as a rare, inherited, recessive disease of skin and mucosa, manifests by forming of trauma-induced bullae - often with subsequent scar formation - and pseudosyndactyly. Involvement of oral and gastrointestinal mucosa include recurrent bullae, scar formation, microstomia and ankyloglossum, shallow vestibular sulci, but also periodontitis, alveolar bone resorption with atrophy of the edentulous areas of maxilla and mandible - all interfering with conventional prosthodontic treatment - and enhanced predisposition for oral squamous cell carcinoma (46).

Data analyses of 27 patients (mean age 35 years) revealed a weighed mean implant survival rate of 98.7 $\%$ after a mean observation period of 33 months. More than $80 \%$ of the jaws were treated with implant-fixed complete or partial dentures, whereas nearly $20 \%$ of the jaws were treated with implant-retained removable overdentures with short dental arch rehabilitation to prevent impeded oral hygiene access due to limited posterior space and mouth opening.

-Systemic Sclerosis

$\mathrm{SSc}$ is an autoimmune multisystem rheumatic disease affecting connective tissue, and an inflammatory, vascular and sclerotic disease of the skin as well as of organs (lung, heart, gastrointestinal tract). Oral and facial clinical findings are mask-like face, thin vermilion border, radial perioral furrows, microstomia, sclerosis of the tongue-tie and induration of the tongue. Hyposalivation, microstomia, ankyloglossia, limited mouth opening but also minor manual skills interfere with oral hygiene ability. While providing with implant-fixed prosthodontic superstructures, reconstructing shortened dental arches, disadvantages of lack of removal of overdentures due to progression of losing manual dexterity and microstomia might be taken into account $(47,48)$. Close cooperation between dental professionals and rheumatologists is necessary for decision making, in treatment planning and maintenance.

Data on dental implant treatment courses of six patients suffering from sSc were available from 6 case reports, revealing a weighed mean implant survival rate of 97.7 $\%$ after a mean observation period of 37.5 months. Implant-fixed complete or partial dentures were used mainly and two patients received implant-retained removable overdentures.

-Pemphigus and systemic Lupus Erythematosus

$\mathrm{Pe}$ is an autoimmune mucocutaneous disease, characterized by epithelial blistering at skin and mucosa, leaving erosions or ulcers following rupturing affecting not only the oral cavity but also the mucosa of nose, conjunctivae, genitals, esophagus, pharynx and larynx.

SLE is a multisystem autoimmune disease with connective tissue and blood vessel disorder, characterized by episodes of recurrent acute or chronic inflammation with intermediate phases of remission, mainly affecting joints, internal organs and skin. Oral manifestations are common - especially during disease flares - and present as forms of painless ulcers (49). Treatment of both Pe and sLE comprises immunosuppressant medications mainly, which may cause adverse effects (among them candida-infections of the oral mucosa) with individually different degree of affection, and dependent on dosage and duration of use. As usual in dental treatment of special needs patients or patients with systemic autoimmune or mucocutaneous diseases, close cooperation of the dentist and the treating specialists is mandatory.

Limited mouth opening and hyposalivation due to secondary Sjögren's syndrome as associated co-morbidity (50) can interfere with wearing of mucosal-borne dentures. Since ill-fitting prostheses or any traumatic contact with the mucosa can cause formation of vesiculobullous or ulcerative lesions, implant-borne stabilization of dentures will result in less trauma and higher patient comfort $(36,37)$.

Only two case reports were found with data on one female patient each with Pe and sLE, both revealing 100 $\%$ implant survival after a follow-up period of at least 24 months, which is too less data to offer any recommendations. However, patients with Pe or sLE seem to benefit from implant-retained or implant-fixed prosthodontic treatment.

\section{Conclusions}

Guidelines regarding implant treatment of patients with oLp, Pe, EB, SjS, sLE or sSc do not exist so far. Results 
of mainly low-evidence publications demonstrate encouraging outcomes regarding dental implant survival, which are comparable to those of healthy patients. Patients with the above mentioned diseases seem to benefit from implant-retained or implant-fixed prostheses. Disease-related contraindicating conditions cannot be defined.

However, for implant-prosthetic rehabilitation of patients with Pe and sLE no conclusions can be drawn due to lack of sufficient clinical data.

Implant-prosthetic treatment guidelines regarding healthy patients should be strictly followed, close recall intervals and full therapy adherence by the patients is required, and close cooperation of the dental professional and the treating specialists is mandatory in patients affected with oLp, Pe, EB, SjS, sLE or sSc.

\section{References}

1. Moraschini V, da C Poubel LA, Ferreira VF, Barboza E dos SP. Evaluation of survival and success rates of dental implants reported in longitudinal studies with a follow-up period of at least 10 years: a systematic review. Int J Oral Maxillofac Surg. 2015;44:377-88.

2. Diz P, Scully C, Sanz M. Dental implants in the medically compromised patient. J Dent. 2013;41:195-206.

3. Esposito M, Thomsen P, Ericson LE, Sennerby L, Lekholm U. Histopathologic observations on late oral implant failures. Clin Implant Dent Relat Res. 2000;2:18-32.

4. Esposito SJ, Camisa C, Morgan M. Implant retained overdentures for two patients with severe lichen planus: a clinical report. J Prosthet Dent. 2003;89:6-10.

5. Öczakir C, Balmer S, Mericske-Stern R. Implant-prosthodontic treatment for special care patients: a case series study. Int J Prosthodont. 2005;18:383-9.

6. Reichart PA. Oral lichen planus and dental implants. Report of 3 cases. Int J Oral Maxillofac Surg. 2006;35:237-40.

7. Hernández G, Lopez-Pintor RM, Arriba L, Torres J, de Vicente JC. Implant treatment in patients with oral lichen planus: a prospective-controlled study. Clin Oral Implants Res. 2012;23:72632.

8. Czerninski R, Eliezer M, Wilensky A, Soskolne A. Oral lichen planus and dental implants--a retrospective study. Clin Implant Dent Relat Res. 2013;15:234-42.

9. López-Jornet P, Camacho-Alonso F, Sánchez-Siles M. Dental implants in patients with oral lichen planus: a cross-sectional study. Clin Implant Dent Relat Res. 2014;16:107-15.

10. Aboushelib MN, Elsafi MH. Clinical management protocol for dental implants inserted in patients with active lichen planus. J Prosthodont. 2017;26:29-33.

11. Anitua E, Pi-as L, Escuer-Artero V, Fernández RS, Alkhraisat MH. Short dental implants in patients with oral lichen planus: a long-term follow-up. Br J Oral Maxillofac Surg. 2018;56:216-20.

12. Payne AG, Lownie JF, Van der Linden WJ. Implant-supported prostheses in patients with Sjögren's syndrome: a clinical report on three patients. Int J Oral Maxillofac Implants. 1997;12:679-85. 13. Isidor F, Brøndum K, Hansen HJ, Jensen J, Sindet-Pedersen $\mathrm{S}$. Outcome of treatment with implant-retained prostheses in patients with Sjögren syndrome. Int J Oral Maxillofac Implants 1999;14:736-43.

14. Binon PP. Thirteen-year follow-up of a mandibular implantsupported fixed complete denture in a patient with Sjögren's syndrome: a clinical report. J Prosthet Dent. 2005;94:409-13.

15. Weinländer M, Krennmair G, Piehslinger E. Implant prosthodontic rehabilitation of patients with rheumatic disorders: a case series report. Int J Prosthodont. 2010;23:22-8.
16. Spinato S, Soardi CM, Zane AM. A mandibular implant-supported fixed complete dental prosthesis in a patient with Sjögren syndrome: case report. Implant Dent 2010;19:178-83.

17. de Mendonca Invernici M, Finger Stadler A, Vale Nicolau G, Naval Machado MA, Adilson Soares de Lima A, et al. Management of Sjogren's Syndrome Patient: A Case Report of Prosthetic Rehabilitation with 6-Year Follow-Up. Case Rep Dent. 2014:761251.

18. Korfage A, Raghoebar GM, Arends S, Meiners PM, Visser A, Kroese FGM, et al. Dental implants in patients with Sjögrens syndrome. Clin Implant Dent Relat Res 2016;18:937-45.

19. Peron C, Fawad J, Romanos GE. Immediate loading of Tantalum-based implants in fresh extraction sockets in patient with Sjögren syndrome: a case report and literature review. Implant Dent 2017;26:634-8.

20. Peñarrocha-Diago M, Serrano C, Sanchis JM, Silvestre FJ, Bagán JV. Placement of endosseous implants in patients with oral epidermolysis bullosa. Oral Surg Oral Med Oral Pathol Oral Radiol Endod. 2000;90:587-90.

21. Lee H, Al Mardini M, Ercoli C, Smith MN. Oral rehabilitation of a completely edentulous epidermolysis bullosa patient with an implant-supported prosthesis: a clinical report. J Prosthet Dent. 2007;97:65-9.

22. Peñarrocha M, Rambla J, Balaguer J, Serrano C, Silvestre J, Bagán JV. Complete fixed prostheses over implants in patients with oral epidermolysis bullosa. J Oral Maxillofac Surg. 2007;65:103-6.

23. Peñarrocha M, Larrazábal C, Balaguer J, Serrano C, Silvestre J, Bagán JV. Restoration with implants in patients with recessive dystrophic epidermolysis bullosa and patient satisfaction with the implant-supported superstructure. Int J Oral Maxillofac Implants. 2007b;22:651-655.

24. Larrazabal-Moron C, Boronat-Lopez A, Peñarrocha-Diago M, Peñarrocha-Diago M. Oral rehabilitation with bone graft and simultaneous dental implants in a patient with epidermolysis bullosa: a clinical case report. J Oral Maxillofac Surg. 2009;67:1499502.

25. Oliveira MA, Ortega KL, Martins FM, Maluf PS, Magalhães MG. Recessive dystrophic epidermolysis bullosa-oral rehabilitation using stereolithography and immediate endosseous implants. Spec Care Dentist. 2010;30:23-6.

26. Müller F, Bergendal B, Wahlmann U, Wagner W. Implant-supported fixed dental prostheses in an edentulous patient with dystrophic epidermolysis bullosa. Int J Prosthodont. 2010;23:42-8.

27. Peñarrocha-Oltra D, Peñarrocha-Diago M, Balaguer-Martínez J, Ata-Ali J, Peñarrocha-Diago M. Full-arch fixed prosthesis supported by four implants in patients with recessive dystrophic epidermolysis bullosa. Oral Surg Oral Med Oral Pathol Oral Radiol Endod. 2011;112:e4-10.

28. Peñarrocha-Oltra D, Aloy-Prósper A, Ata-Ali J, PeñarrochaDiago M, Peñarrocha-Diago M. Implants placed simultaneously with particulated bone graft in patients diagnosed with recessive dystrophic epidermolysis bullosa. J Oral Maxillofac Surg. 2012;70:e51-7.

29. Augustin-Panadero R, Gomar-Vercher S, Peñarrocha-Oltra D, Guzmán-Letelier M, Peñarrocha-Diago M. Fixed full-arch implant-supported prostheses in a patient with epidermolysis bullosa: a clinical case history report. Int J Prosthodont. 2015;28:33-6. 30. Augustin-Panadero R, Serra-Pastor B, Peñarrocha-Oltra D, Peñarrocha-Diago M. Maxillary implant prosthodontic treatment using digital laboratory protocol for a patient with epidermolysis bullosa: a case history report. Int J Prosthodont. 2017;30:390-3.

31. Alikhasi M, Sharifi R, Falahchai SM. Combined digital/conventional technique for rehabilitation of a patient with epidermolysis bullosa. A case letter. J Oral Implantol. 2017;43:387-91.

32. Jensen J, Sindet-Pedersen S. Osseointegrated implants for prosthetic reconstruction in a patient with scleroderma: report of a case. J Oral Maxillofac Surg. 1990;48:739-41.

33. Raviv E, Harel-Raviv M, Shatz P, Gornitsky M. Implant-sup- 
ported overdenture rehabilitation and progressive systemic sclerosis. Int J Prosthodont. 1996;9:440-4.

34. Zigdon H, Gutmacher Z, Teich S, Levin L. Full-mouth rehabilitation using dental implants in a patient with scleroderma. Quintessence Int. 2011;42:781-5.

35. Baptist BA. Fixed implant supported rehabilitation of partially edentulous posterior maxilla in a patient with systemic scleroderma: a case report. Implant Dent. 2016;25:155-9.

36. Altin N, Ergun S, Katz J, Sancakli E, Koray M, Tanyeri H. Implant-supported oral rehabilitation of a patient with pemphigus vulgaris: a clinical report. J Prosthodont. 2013;22:581-6.

37. Ergun S, Katz J, Cifter ED, Koray M, Esen BA, Tanyeri H. Implant-supported oral rehabilitation of a patient with systemic lupus erythematosus: case report and review of the literature. Quintessence Int 2010;41:863-7.

38. Holmstrup P, Plemons J, Meyle J. Non-plaque-induced gingival diseases. J Clin Periodontol. 2018;45 (Suppl 20):28-43.

39. Di Stasio D, Guida A, Salerno C, Contaldo M, Esposito V, Laino L, et al. Oral lichen planus: a narrative review. Front Biosci (Elite Ed). 2014;6:370-6.

40. Serrano J, Lopéz-Pintor RM, González-Serrano J, FernándezCastro M, Casañas E, Hernández G. Oral lesions in Sjögren's syndrome: a systematic review. Med Oral Patol Oral Cir Bucal. 2018;23:e391-400.

41. Fatoye F, Gebrye T, Svenson LW. Real-world incidence and prevalence of systemic lupus erythematosus in Alberta, Canada. Rheumatol Int. $2018 \mathrm{Jul}$ 9. [Epub ahead of print]

42. Fine JD. Epidemiology of inherited epidermolysis bullosa based on incidence and prevalence estimates from the national epidermolysis bullosa registry. JAMA Dermatol. 2016;152:12318.

43. Royle JG, Lanyon PC, Grainge MJ, Abhishek A, Pearce FA. The incidence, prevalence, and survival of systemic sclerosis in the UK clinical practice research datalink. Clin Rheumatol. 2018;37:2103-11.

44. Hübner F, Recke A, Zillikens D, Linder R, Schmidt E. Prevalence and age distribution of pemphigus and pemphigoid diseases in Germany. J Invest Dermatol. 2016;136:2495-8.

45. Candel-Marti ME, Ata-Ali J, Peñarrocha-Oltra D, Peñarrocha-Diago M, Bagán JV. Dental implants in patients with oral mucosal alterations: An update. Med Oral Patol Oral Cir Bucal. 2011;16:e787-93.

46. Fine JD. Inherited epidermolysis bullosa: past, present, and future. Ann N Y Acad Sci. 2010;1194:213-22.

47. Patel K, Welfare R, Coonar HS. The provision of dental implants and a fixed prosthesis in the treatment of a patient with scleroderma: a clinical report. J Prosthet Dent. 1998;79:611-612. 48. Baron M, Hudson M, Tatibouet S, Steele R, Lo E, Gravel $\mathrm{S}$, et al. Relationship between disease characteristics and orofacial manifestations in systemic sclerosis: Canadian Systemic Sclerosis Oral Health Study III. Arthritis Care Res (Hoboken). 2015;67:681-90.

49. Petri M, Orbai AM, Alarcón GS, Gordon C, Merrill JT, Fortin $\mathrm{PR}$, et al. Derivation and validation of the Systemic Lupus International Collaborating Clinics classification criteria for systemic lupus erythematosus. Arthritis Rheum. 2012;64:2677-86.

50. Lehman TJ. A practical guide to systemic lupus erythematosus. Pediatr Clin North Am. 1995;42:1223-38.

\section{Conflicts of Interests}

No funding nor other financial nor other support was received by any author with regard to this systematic review. All authors declare no conflict of interests. 